\title{
Teaching Young FL Learners New Vocabulary: A Comparison between the Efficiency of Keyword Method and Total Physical Response
}

\author{
Dacian Dorin Dolean ${ }^{1} \&$ Andreea Dolghi ${ }^{1}$ \\ ${ }^{1}$ Babes-Bolyai University, Cluj-Napoca, Romania \\ Correspondence: Dacian Dolean, Faculty of Psychology and Educational Sciences, Babes-Bolyai University, Str. \\ Sindicatelor nr. 7, 400029 Cluj-Napoca, Romania. E-mail: dorin.dolean@ubbcluj.ro
}

Received: September 2, 2016 Accepted: September 30, 2016 Online Published: November 23, 2016

doi:10.5539/ijel.v6n6p1 URL: http://dx.doi.org/10.5539/ijel.v6n6p1

\begin{abstract}
Teaching a foreign language to young children has been an increasingly dominant trend in most globalized societies. While there is abundant literature that supports teaching a foreign language at an early age through language immersion programs, little is known about the efficiency of strategies used to explicitly teach new vocabulary words in a foreign language to young learners. This empirical investigation aimed to assess and compare the efficiency of two mnemonics that have been traditionally used to explicitly teach new foreign language words: the Keyword Method (KWM) and the Total Physical Response (TPR). Results indicate that the KWM is more effective than TPR in teaching new vocabulary words in a foreign language to early elementary school children.
\end{abstract}

Keywords: keyword method; total physical response; foreign language vocabulary; early elementary school

\section{Introduction}

One of the contemporary realities that many school systems face in globalized societies around the world is that parents expect their children to take foreign language (FL) classes at an earlier age now than they did in past decades (e.g., Special Eurobarometer 243, 2006). Despite an abundance of literature supporting the effectiveness of language immersion programs (Gebauer, Zaunbauer, \& Moller, 2013; Genesse \& Jared, 2008; Hermanto, Moreno, \& Bialystok, 2012) as a strategy to help young children learn a FL implicitly (DeKeysser, 2003; Dolean, 2015), few studies address the efficiency of formal (explicit) teaching of a foreign language during the early elementary school years.

Among the first and most important steps to be taken towards formal teaching of a FL is teaching its vocabulary (Folse, 2004; Nation, 2001). Given that this task requires learners to have solid mnemonic abilities and a rather high level of meta-cognitive abilities in order to encode the information in different ways (e.g., semantically, through phonemic associations, or through imagery), many elementary school students fail to perform as well as their older peers (for a comprehensive review, see Monoz \& Singleton, 2011). However, teachers can enhance student learning by using mnemonics when explicitly teaching vocabulary words in a FL (Dolean, 2013). Two of these mnemonic strategies are the Keyword Method (KWM) and Total Physical Response (TPR). Despite the fact that there is abundant evidence supporting the use of both strategies in teaching FL vocabulary, there are no empirical studies that compare the effectiveness of the two strategies when they are used to teach new vocabulary words in a FL to young learners. Our study aims to conduct such a comparative analysis through an empirical investigation.

\section{Literature Review}

\subsection{The Keyword Method}

The Keyword Method (KWM) is one of the most extensively researched mnemonics used in teaching FL vocabulary. Several empirical studies (e.g., Atkinson \& Raugh, 1975; Beaton, Gruneberg, Hyde, Shufflebottom, \& Sykes, 2005; Sagarra \& Alba, 2006; Shapiro \& Waters, 2005) have shown that the retention of a new vocabulary word in a FL (e.g., the Spanish word carta, meaning letter) can be substantially increased when the learner associates its sound to a keyword in his/her native language (e.g., the English word cart), and then 
creates a mental image combining the two words (e.g., a letter in a cart). Some authors found it helpful, especially in teaching children, to facilitate the formation of the mental image by providing learners with an interactive picture of the two words (e.g., Avila \& Sadoski, 1996; Wyra, Lawson, \& Hungi, 2007). However, the KWM proved to be very effective even without the emphasis on the interactive imagery, as long as certain criteria were considered in the selection of the two words. These criteria include, a high degree of phonemic overlapping, a high imagery value, and a high concreteness value (Dolean, 2014).

Although the efficiency of the KWM is generally recognized by most scholars, some critics indicate that the method is less efficient than traditional learning methods when it is used by experienced foreign language learners or older students (Hogben \& Lawson, 1994; Van Hell \& Mahn, 1997; Wei, 2015). Indeed, the KWM tends to be more efficient when it is used to teach young students than when it is used with their older peers (Dolean, 2014). These findings support the use of the KWM to explicitly teach new vocabulary words in a FL to children registered in early elementary school programs.

\subsection{Total Physical Response}

Another popular mnemonic strategy used for teaching FL vocabulary is the Total Physical Response (TPR) developed by Asher (1966). When using this method, FL instructors give a series of commands in the target language (e.g., jump and clap your hands), while learners are expected to respond with whole-body movements (e.g., to jump while clapping their hands). TPR is supported by several theoretical approaches to learning situations. For instance, Dale's (1969) Audiovisual Methods in Teaching claims that students learn most efficiently when all of their senses are engaged in the learning process, while The Natural Approach (Krashen \& Terrell, 1986) claims that children learn a second language more effectively when they learn it naturally, in a stimulating environment that facilitates a low affective filter and encourages a progressive development from language comprehension to language production.

Experimental studies that focused on the efficiency of teaching a FL using the TPR method indicated that TPR can lead to a significant increase in the vocabulary acquisition and listening comprehension skills of FL learners when compared with the control groups (Asher, 1969; Asher \& Price, 1967; Asher, Kusudo, \& de la Torre, 1974; Kunihira \& Asher, 1965). Given that children registered in early elementary school are not developmentally prepared to focus and sustain attention for long periods of time while staying still in their seats (Matusz et al., 2015), and that learning at this age is usually more kinesthetically-oriented (Vetter, O'Connor, O'Dwyer, \& Orr, 2015) using TPR to teach FL vocabulary seems to be an age-appropriate and efficient method for elementary school FL classrooms.

\section{The Present Study}

Despite the popularity of the two aforementioned mnemonics, we know very little about how efficient one method is compared with the other when teaching new vocabulary words in a FL. Therefore, in the present study we aimed to assess comparatively the efficiency of the KWM and TPR (as experimental conditions), and to compare both of these methods with a more traditional and frequently used method in the FL classroom: the association of the sound of a new word with a picture (P) representing its meaning (as a control condition). To prevent confounding variables generated by inter-subjects variability, we have used a within-subjects experimental design, while also accounting for the number of syllables, imagery and concreteness value of each vocabulary word. Hence, this paper aimed to answer the following research question:

How does the effectiveness of the KWM compare with TPR when teaching new vocabulary words in a FL to early elementary school children?

\section{Method}

\subsection{Participants}

Thirty-four early elementary school children (ages 6-7, 11 boys, 23 girls) from 3 different Romanian rural schools were selected to participate in this study. The schools were randomly selected among those who did not offer English learning programs before 3rd grade, and whose student populations had a very limited exposure to English. None of the children had previously experienced any formal English language lesson, at school or at home. All children were monolingual, and none of them had ever been immersed in an English speaking environment. All participating children reported that they had TV access at home, and that they watched cartoons dubbed in Romanian. None watched television programs in English. Five students did not have a home computer, and among those who did own a computer, all reported that they used it only for listening to music and playing games. None of them reported having used any English language learning software. 


\subsection{Items Selection}

A total of 30 concrete English nouns were selected and grouped into three different lists of 10. All words were matched by the number of syllables, imagery value and concreteness value (Paivio, Yuille, \& Madigan, 1968) in order to control for potential confounds generated by the use of different words (see also Dolean, 2014; Saggara \& Alba, 2006). Prior to the experiment, 10 native Romanian speakers with college education level rated the imagery value of the three groups of words on a scale from 1 (very difficult to visualize) to 7 (very easy to visualize). Means and standard deviations scores are displayed in Table 1 . The imagery score of the three treatments indicated that the words had a high imagery value. They also indicated that there was no significant difference between KWM and TPR [ $\mathrm{t}(18)=-.82, \mathrm{p}>.05]$, between KWM and $\mathrm{P}[\mathrm{t}(18)=-.24, \mathrm{p}>.05)$ and between TPR and $\mathrm{P}[\mathrm{t}(18)=.69, \mathrm{p}>.05]$. Similarly, the 10 native Romanian speakers rated the word lists for concreteness from 1 (abstract) to 7 (concrete). The words rated highly on the concreteness scale (see Table 1), and there was no significant difference between KWM and TPR [t $(18)=-.25, \mathrm{p}>.05]$, between KWM and P $[\mathrm{t}(18)=-.57, \mathrm{p}>.05)$, and between TPR and $\mathrm{P}[\mathrm{t}(18)=-.35, \mathrm{p}>.05]$.

Table 1. Mean (and Standard Deviation) of imagery and concreteness scores of the words from KWM, TPR and $P$ treatments

\begin{tabular}{llll}
\hline & KWM & TPR & P \\
\hline Imagery & $6.38(.31)$ & $6.49(.28)$ & $6.41(.23)$ \\
Concreteness & $6.09(.26)$ & $6.12(.20)$ & $6.15(.14)$ \\
\hline
\end{tabular}

In order to optimize the learning effect in the KWM treatment, the paired items (each new word with its keyword) were selected to have a high degree of phonemic overlapping (e.g., the English word "wall" and the Romanian word "oala", translated "cooking pot"). In order to optimize the learning effect in the TPR treatment, the vocabulary words selected were all body parts. None of the English words had a pronunciation similar to its Romanian translation.

\subsection{Materials}

Two booklets (paper size $30 \mathrm{~cm} \times 21 \mathrm{~cm}$ ) were used in this experiment. The first booklet was used in the KWM treatment and included 10 sets of paired pictures, each set displayed on opposite ends of the page. One picture from the set represented the meaning of the new word (e.g., bread) and the other picture represented the meaning of its keyword (e.g., fir tree, translated "brad" in Romanian). The second booklet was used in P treatment and included 10 pictures, one picture on each page, representing the meaning of the new word (e.g., hook). The size of pictures used in KWM treatment matched the size of pictures presented in P treatment. No visual materials were used in the TPR treatment.

\subsection{Procedure}

The experiment was conducted in four stages: initial assessment, intervention, next day assessment, and two-weeks-later assessment.

\subsubsection{Initial Assessment}

Each participating child's vocabulary knowledge of the 30 words to be learned was assessed individually prior to the intervention. The assessment took place in a quiet room within each school. Besides the test administrator, one testing assistant and the participating child, there were no other people in the room. On the testing room walls, no pictures representing the new words were displayed.

The test administrator read a standardized set of instructions to each participating child, in which she informed the participant that he/she would hear 30 words in English. If the child knew the Romanian translation of any of the words, he/she was asked to say it out loud. If he/she didn't know it, he/she was asked to indicate that by saying "I don't know". Then, the test administrator read the words one by one, and marked the child's answers. None of the children recognized/translated correctly from English to Romanian any of the 30 words to be learned. Then, the administrator showed each child an image of each word, and asked the child to say in Romanian what it represented. The pictures were shown in a different order than the previously read words. The images were displayed on a standard paper $(30 \times 21 \mathrm{~cm})$. All children were able to identify correctly and say the Romanian word for the pictures shown by the test administrator.

\subsubsection{Intervention}

Each group of students from the three selected schools had a one-time English lesson aimed to help them learn 
30 English vocabulary nouns (see items description below). The lesson consisted of a 30-minute group activity conducted in the regular classroom. The intervention teacher was an experienced and certified kindergarten and ESL teacher. Each intervention was conducted with groups of 10-14 children.

The vocabulary words were introduced in one of the three treatments, as follows: Keyword Method (KWM) treatment (10 words), Total Physical Response (TPR) treatment (10 words), and Picture (P) treatment (10 words).

During the KWM treatment, a picture representing the meaning of the new to-be-learned word was presented to children together with a (non-interacting) picture representing a keyword (a word that sounded similar to the new word). For instance, the image of a cup was associated to an image of a head (translated "cap" in Romanian). While the pictures were shown, the teacher sounded out the correct pronunciation of the English word, and pointed out the similarity in pronunciation between the new word and the keyword. All words were presented 3 times each.

During the TPR treatment, the teacher first played "Simon says..." in Romanian using Romanian body parts (e.g., Simon says touch your belly). After 5 minutes she told children that she will say the name of the body parts (and only the name of the body parts, but not the instruction) in English (e.g., "Atinge"-Romanian for the word "touch" - "head"). While she said that, she touched the corresponding body part, and children did the same while doing their best to memorize the new word. All body parts were presented 3 times each.

During the P treatment, the teacher showed the children a single picture of the new word while sounding out its English translation. In this treatment, the picture of each new word was shown, without the keyword image. All words were presented 3 times each.

Students did not utter any words during any of the treatments. They only listened to the visual presentations or executed the required movements by listening to the teacher. During the first 10 minutes of the intervention, the teacher introduced five words in $\mathrm{K}$ treatment and five words in $\mathrm{P}$ treatment. Then, in the following 10 minutes, the 10 TPR words were introduced, by performing the game "Simon Says...". During the last 10 minutes of the intervention, the remaining five $\mathrm{K}$ treatment and five $\mathrm{P}$ treatment words were presented. After a two-minute break, the teacher reviewed the 30 new words by presenting each word again in each treatment before ending the lesson. In total, there were 4 repetitions of each word.

\subsubsection{Next-day Assessment}

The day following the intervention, each child was assessed again under the same conditions he/she had been assessed under prior to the intervention. The performance was assessed by the same test administrator, who had performed the intervention as well. She read each new word in English to each child, and asked him/her to say the Romanian translation, to the best of their ability. If the child did not know the translation, he/she was asked to say "I don't know".

\subsubsection{Two-weeks-later Assessment}

The assessment procedure was repeated two weeks after the intervention. The assessment administration procedure was identical to the procedure of the previous assessment.

\section{Results}

Descriptive statistics representing the mean (and standard deviation) scores of the recalled performance computed as percentages are shown in Table 2 .

Table 2. Mean percentage (and standard deviation) of recalled vocabulary words in KWM, TPR and P treatments, one day (T1) and two weeks (T2) after the intervention

\begin{tabular}{llll}
\hline & KWM & TPR & P \\
\hline T1 & $33.53(21.02)$ & $4.41(7.05)$ & $9.12(11.64)$ \\
T2 & $30.29(22.63)$ & $5.59(9.27)$ & $7.35(10.24)$ \\
\hline
\end{tabular}

A 2 (time) x 3 (treatment) repeated-measures analysis of variance (ANOVA) was conducted, to compare the recall performance (percent correct) of participants from the experimental and control treatments. The analysis indicated no significant main effect for time $F(1,33)=3.04, p>.05, \eta_{p}{ }^{2}=.084$, but significant main effect for treatment $F(2,66)=58.11, p<.001, \eta_{p}{ }^{2}=.638$. Results also indicated no significant interaction effect for time and treatment $F(2,66)=3.15, p>.05, \eta_{p}{ }^{2}=.087$. Post-hoc pairwise comparisons with Bonferroni corrections 
indicated that the learning performance of vocabulary words presented in KWM treatment was significantly better $(p<.05)$ than the words presented in TPR and P treatment, and there was no significant difference in performance between TPR and P treatments $(p>.05)$ (see Table 2).

\section{Discussion}

The present study aimed at assessing the efficiency of the Keyword Method and the Total Physical Response Method when teaching new vocabulary words in a foreign language, compared with a more traditional method consisting of simultaneously modeling the correct pronunciation of the new word while presenting the learners with a picture representing its meaning.

Results indicate that the KWM is more effective than TPR in teaching new vocabulary words in a FL when the new words are concrete nouns with high imagery value, and when the new word and its keyword have a high degree of phonemic overlapping. The fact that students are engaging their whole bodies in the learning process (Dale, 1969; Krashen \& Terrell, 1986) does not necessarily lead to better cognitive performance when compared with the benefits provided by the visual association of the new word with a keyword (Atkinson \& Raugh, 1975). To the best of our knowledge, this is the first empirical investigation that compares the efficiency of the two methods and leads to such a conclusion. Yet, in order to confidently generalize these results, further investigations are deemed necessary using a greater variety of items, age groups and learning situations.

Surprisingly, results indicated no significant effect for treatment when we compared the TPR with the P treatment. On one hand, this may suggest that TPR is not as efficient as originally believed, and even though the method seems to be very age-appropriate and entertaining, the learning effect seems rather modest. On the other hand, the results may suggest that the visual stimuli from the $\mathrm{P}$ treatment can have a strong positive effect on learning. This is explained by Paivio's (1971) dual-code theory which postulates that visual and verbal information is processed by two different cognitive mechanisms (verbal and visual), and when people intend to recall the information, they have a better chance of retrieving it from long-term memory if the information is coded both ways. Paivio's theory is also supported by classical empirical investigations that suggest that visual stimuli produce strong memories (Shepard, 1967, Standing 1973); thus, presenting a to-be-learned item (a new word) to students both verbally (sounding out the correct pronunciation) and visually (showing a picture of the item) would increase the learning performance of that word, which justifies the high performance of the $\mathrm{P}$ treatment.

The results indicating a large size of the main effect for treatment and the fact that the recall performance of the KWM treatment was more than 3 times higher than the recall performance of the P treatment suggest that the former method can be very effective in teaching young children. Indeed, previous investigations suggest that the younger the age group, the more efficient the method can be in teaching new vocabulary words. This is not because young students would have a better performance than their older counterparts, but because the efficiency of explicitly teaching a foreign language using more traditional methods (like the $\mathrm{P}$ method) tends to be lower (Dolean, 2014). These findings add to the existing literature and support the use of the KWM in the classroom, especially when it is being used to teach young children and when visual support is being provided.

The results indicating no significant effect for time suggest that the forgetting rate is highest within 24 hours after the items are presented, supporting experiential evidence that indicate a high forgetting rate in young learners soon after stimulation (e.g., Bayliss, Jarrold, \& Greene, 2015; Brainerd \& Reyna, 1995). These findings suggest that FL instructors teaching elementary school children should be aware of the limitations of their memory skills and of the importance of mnemonics and their role in scaffolding the learning process. Furthermore, the results indicating no interaction effect between time and treatment do not support medium-term efficiency of one particular method when compared with the others, and do not support claims of a poor performance rate of the KWM in the long term (Wang, 1995).

The conclusions of our study need to be treated with caution due to two limitations. First, given that the items from the KWM and TPR treatments were selected in order to optimize their efficiency, we cannot know whether there will be similar effects when items are used in less-than-optimal conditions, such as using the KWM to teach adjectives (e.g., beautiful) or using TPR to teach more abstract words (e.g., soul). Thus, the generalizability of our findings is limited, and more studies are deemed necessary to explore the relationship between the two mnemonics. Second, although our results suggest that the KWM can increase learning performance significantly, the fact that we cannot always find a keyword to associate with a new vocabulary word limits the possibilities of using the KWM when teaching vocabulary words in a foreign language. 


\section{Conclusion}

Our study suggests that if FL teachers explicitly teach vocabulary words in a FL to young students, they can significantly improve students' retention performance by using the KWM when high-quality keywords are available, even if the paired pictures are not interacting with each other and that this method leads to superior performance when compared with TPR. The study also indicates that, although using an interactive method like TPR to teach young children vocabulary words can be age-appropriate and entertaining, the assumed efficiency of such a method (compared with more traditional methods, such as single picture presentation) needs to be treated with caution.

\section{Acknowledgements}

This research was funded by Babes-Bolyai University, "Granturi pentru Tineri Cercetatori 2016", contract number 31789/23.03.2016.

\section{References}

Asher, J. (1966). The learning strategy of the Total Physical Response: A review. The Modern Language Journal, 53(1), 79-84. http://dx.doi.org/10.2307/323182

Asher, J. (1969). The total physical approach to second language learning. The Modern Language Journal, 53(1), 3-17.

Asher, J., \& Ben, S. P. (1967). The learning strategy of Total Physical Response: Some Age Differences. Child Development, 38(4), 1219-1227. http://dx.doi.org/10.2307/1127119

Asher, J., Kusudo, J. A., \& de la Torre, R. (1974). Learning a second language through commands: The second field test. The Modern Language Journal, 58(1-2), 24-32. http://dx.doi.org/10.2307/323986

Atkinson, R. C., \& Raugh, M. M. (1975). An application of the mnemonic keyword method to the acquisition of Russian vocabulary. Journal of Experimental Psychology: Human Learning and Memory, 104, 126-133. http://dx.doi.org/10.1037/0278-7393.1.2.126

Avila, E., \& Sadoski, M. (1996). Exploring New Applications of the Keyword Method to Acquire English Vocabulary. Language Learning, 46(3), 379-395. http://dx.doi.org/10.1111/j.1467-1770.1996.tb01241.x

Bayliss, D. M., Jarrold, C., \& Greene, R. (2015). How quickly they forget: The relationship between forgetting rate and working memory performance. Journal of Experimental Psychology: Learning, Memory, and Cognition, 4l(1), 163-177. http://dx.doi.org/10.1037/a0037429

Brainerd, C. J., \& Reyna, V. F. (1995). Learning rate, learning opportunities, and the development of forgetting. Developmental Psychology, 31(2), 215-262. http://dx.doi.org/10.1037/0012-1649.31.2.251

Dale, E. (1969). Audio-Visual Methods in Teaching (3rd ed.). New York: Holt, Rinehart \& Winston.

DeKeyser, R. (2003). Implicit and explicit learning. In Doughty \& Long (Eds.), The Handbook of Second Language Acquisition (pp. 313-348). Oxford: Blackwell Publishing Ltd. http://dx.doi.org/10.1002/9780470756492.ch11

Dolean, D. D. (2013). Mnemonics used in learning concepts in English as a foreign language. In M. Ionescu (Ed.), Studii de pedagogie aplicata, Cap. 6. Cluj-Napoca: Eikon.

Dolean, D. D. (2014). Using the Keyword Method in the classroom: Is the interacting imagery necessary? System, 45, 17-26. http://dx.doi.org/10.1016/j.system.2014.04.003

Dolean, D. D. (2015). How early can we efficiently teach a second language? European Early Childhood Education Research Journal, 23(5), 706-719. http://dx.doi.org/10.1080/1350293X.2015.1104047

Folse, K. (2004). Vocabulary Myths: Applying Second Language Research to Classroom Teaching. Ann Arbor: The University of Michigan Press. http://dx.doi.org/10.3998/mpub.23925

Gebauer, S. K., Zaunbauer, A. C. M., \& Moler, J. (2013). Cross-language transfer in English immersion programs in Germany: Reading comprehension and reading fluency. Contemporary Educational Psychology, 38, 64-74. http://dx.doi.org/10.1016/j.cedpsych.2012.09.002

Genesee, F., \& Jared, D. (2008). Literacy development in early French immersion programs. Canadian Psychology, 49(2), 140-147. http://dx.doi.org/10.1037/0708-5591.49.2.140

Hermanto, N., Moreno, S., \& Bialystok, E. (2012). Linguistic and metalinguistic outcomes of intense immersion education: how bilingual? International Journal of Billingual Education and Billingualism, 15(2), 131-145. 
http://dx.doi.org/10.1080/13670050.2011.652591

Hogben, D., \& Lawson, M. J. (1994). Keyword and multiple elaboration strategies for vocabulary acquisition in foreign language learning. Contemporary Educational Psychology, 19, 367-376. http://dx.doi.org/10.1006/ceps.1994.1027

Krashen, S. D., \& Terrell, T. D. (1983). The natural approach: Language acquisition in the classroom. Essex: Pearson Education Limited.

Kunihira, S., \& Asher, J. J. (1965). The strategy of the total physical response: An application to learning Japanese. International Review of Applied Linguistics, 3(4), 277-289. http://dx.doi.org/10.1515/iral.1965.3.4.277

Matusz, P. J., Broadbent, H., Ferrri, J., Forrest, B., Merkley, R., \& Scerif, G. (2015). Multi-modal distraction: Insights from children's limited attention. Cognition, 136, 156-165. http://dx.doi.org/10.1016/j.cognition.2014.11.031

Muñoz, C., \& Singleton, D. (2011). A critical review of age-related research on L2 ultimate attainment. Language Teaching, 44, 1-35. http://dx.doi.org/10.1017/S0261444810000327

Nation, I. S. P. (2001). Learning Vocabulary in Another Language. Cambridge: Cambridge University Press. http://dx.doi.org/10.1017/CBO9781139524759

Paivio, A. (1971). Imagery and Verbal Process. New York: Holt, Rinehart and Winston.

Paivio, A., Yuille, J. C., \& Madigan, S. A. (1968). Concreteness, imagery, and meaningfulness values for 925 nouns. Journal of Experimental Psychology, 76(2). http://dx.doi.org/10.1037/h0025327

Sagarra, N., \& Alba, M. (2006). The Key in the keyword: L2 vocabulary learning methods with beginning learners of Spanish. The Modern Language Journal, 90(6), 228-243. http://dx.doi.org/10.1111/j.1540-4781.2006.00394.x

Shepard, R. N. (1967). Recognition memory for words sentences and pictures. Journal of Verbal Learning and Verbal Behavior, 6, 156-163. http://dx.doi.org/10.1016/S0022-5371(67)80067-7

Special Eurobarometer 243. (2006). Europeans and their languages. Retrieved from http://ec.europa.eu/public_opinion/archives/ebs/ebs_243_en.pdf

Standing, L. (1973). Learning 10,000 Pictures. Quarterly Journal of Experimental Psychology, 25, 207-222. http://dx.doi.org/10.1080/14640747308400340

Van Hell, J. G., \& Mahn, A. C. (1997). Keyword mnemonics versus rote rehearsal: learning concrete and abstract foreign words by experienced and inexperienced learners. Language Learning, 47(3), 507-546. http://dx.doi.org/10.1111/0023-8333.00018

Vetter, H., O’Connor, N., O'Dwyer, R., \& Orr, R. (2015). Active learning: Effectiveness of learning a numeracy skill with physical activity, reducing sedentary time in school children. Journal of Science and Medicine in Sport, 19(e12). http://dx.doi.org/10.1016/j.jsams.2015.12.408

Wang, A. Y., \& Thomas, M. H. (1995). Effect of keywords on long-term retention: help or hindrance? Journal of Educational Psychology, 87, 468-475. http://dx.doi.org/10.1037/0022-0663.87.3.468

Wei, Z. (2015). Does teaching mnemonics for vocabulary learning make a difference? Putting the keyword method and the word part technique to test. Language Teaching Research, 19, 43-69. http://dx.doi.org/10.1177/1362168814541734

Wyra, M., Lawson, M. J., \& Hungi, N. (2007). The mnemonic keyword method: The effects of bidirectional retrieval training and of ability to image on foreign language vocabulary recall. Learning and Instruction, 17, 360-371. http://dx.doi.org/10.1016/j.learninstruc.2007.02.008

\section{Copyrights}

Copyright for this article is retained by the author(s), with first publication rights granted to the journal.

This is an open-access article distributed under the terms and conditions of the Creative Commons Attribution license (http://creativecommons.org/licenses/by/4.0/). 